\title{
A framework to quantify riverine dissolved inorganic nitrogen exports under changing land use pattern and hydrologic regime
}

\author{
Zhenyu Zhang ${ }^{1}$, Jr-Chuan Huang ${ }^{2}$, and Jinliang Huang ${ }^{1}$ \\ ${ }^{1}$ Xiamen University \\ ${ }^{2}$ National Taiwan University
}

December 29, 2020

\begin{abstract}
Riverine dissolved inorganic nitrogen (DIN), when elevated by human activities (e.g., land-use change), can accelerate the nitrogen cycle and downstream dispersal. However, estimating DIN export coefficients for individual land-use types can be complex due to mosaic land-use patterns and interactions between fertilizers and hydrological processes. We propose a framework that integrates an empirical model, a moving-window method with an elasticity method to quantify seasonal DIN export coefficients for each land use in the Shixi Creek catchment, southeast China. Our model showed good agreement with field observations according to root mean square error and a normalized objective function. The DIN export coefficients of farmland and forest were the highest $(9.16 \mathrm{mg} / \mathrm{L})$ and lowest $(2.91 \mathrm{mg} / \mathrm{L})$, respectively, resulting in DIN exports for farmland and forest of $1,951 \mathrm{~kg} \mathrm{~km}-2 \mathrm{yr}-1$ and $619 \mathrm{~kg} \mathrm{~km}-2 \mathrm{yr}-1$, respectively. Urbanization was a dominant factor influencing DIN export represented by the export coefficient of built-up areas with the highest elasticity and highest uncertainty. This study can shed light on how to improve riverine $\mathrm{N}$ management in a catchment by considering the interactive effects of climate and land use changes.
\end{abstract}

\section{Hosted file}

final_mauscript.pdf available at https://authorea.com/users/385938/articles/501181-aframework-to-quantify-riverine-dissolved-inorganic-nitrogen-exports-under-changing-

land-use-pattern-and-hydrologic-regime 

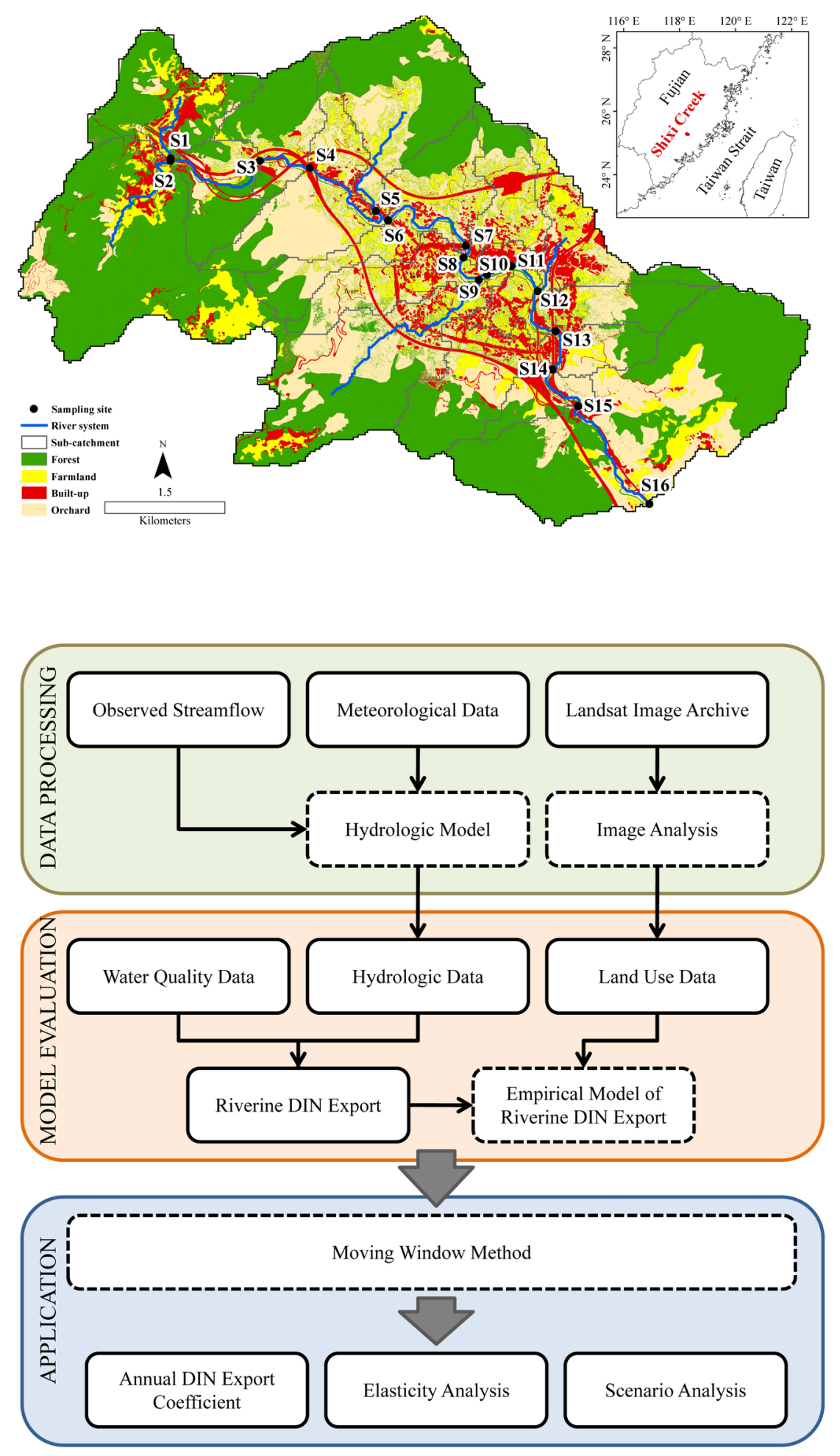

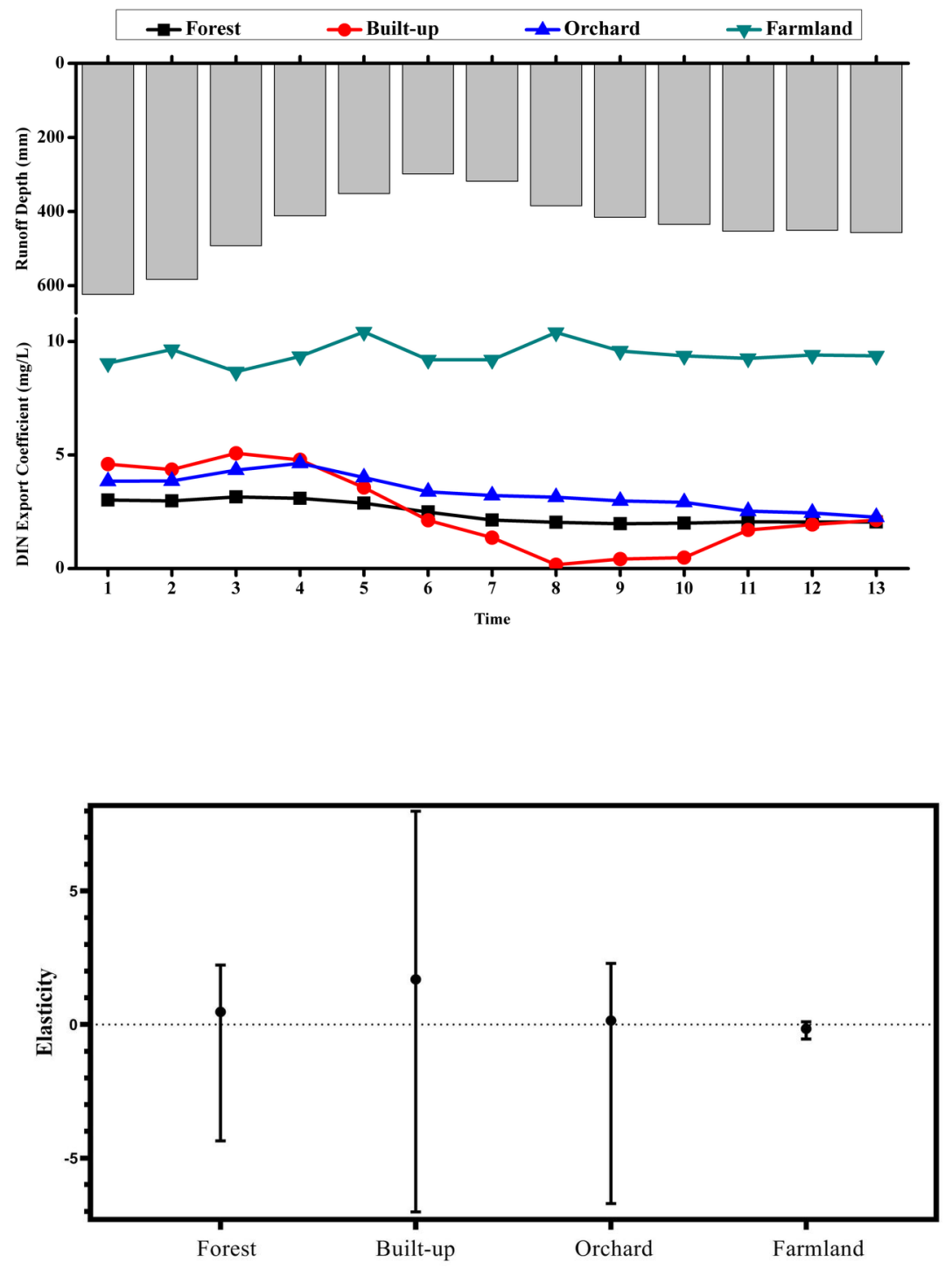


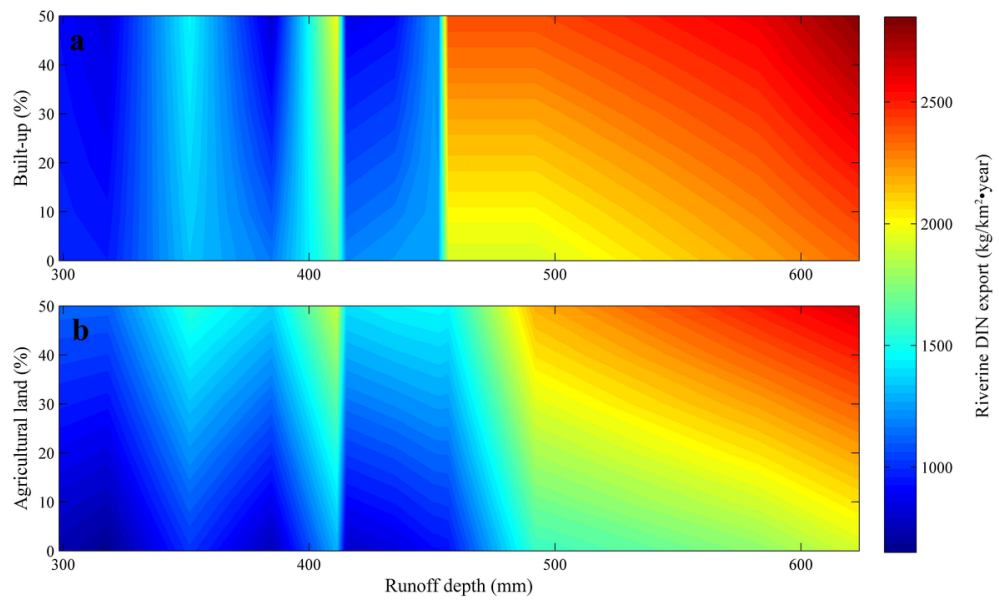

\section{Hosted file}

table1.xls available at https://authorea.com/users/385938/articles/501181-a-framework-toquantify-riverine-dissolved-inorganic-nitrogen-exports-under-changing-land-use-patternand-hydrologic-regime

\section{Hosted file}

table2.xls available at https://authorea.com/users/385938/articles/501181-a-framework-toquantify-riverine-dissolved-inorganic-nitrogen-exports-under-changing-land-use-patternand-hydrologic-regime

\section{Hosted file}

table3.xls available at https://authorea.com/users/385938/articles/501181-a-framework-toquantify-riverine-dissolved-inorganic-nitrogen-exports-under-changing-land-use-patternand-hydrologic-regime 